\title{
Origin of Aschoff Nodule \\ An Ultrastructural, Light Microscopic and Histochemical Evaluation
}

\author{
Prem Chopra, M.D.
}

\begin{abstract}
Summary
Excised left atrial appendages were subjected to light and electron microscopy and histochemical analysis. Aschoff nodules (AN) showed strong acid phosphatase and nonspecific esterase activity. Ultrastructurally, the Aschoff cells had several features of fibroblasts and epithelioid cells. Rough endoplasmic reticulum (RER) was striking in most cells. Dilated cisterns of RER containing homogeneous material were also frequent. Mitochondria and ribosomes were present. AN thus seem to arise from mesenchymal tissues of the heart. It is likely that cross-reactivity between streptocococcal antigen and myocardial connective tissue causes the cardiac histocyte/macrophage to transform to cells having features of epithelioid cells and/or fibroblasts.
\end{abstract}

\section{Additional Indexing Words:}

Left atrial appendage Aschoff cells Rheumatic heart disease Epithelioid cells Macrophages Fibroblasts

\begin{abstract}
SCHOFF nodules (AN) are a histological feature of rheumatic heart A disease (RHD). Although this is generally accepted, there is some controversy as to the origin of AN. Cells comprising AN have been claimed to originate from a variety of mesenchymal cells, namely, cardiac fibres, ${ }^{11}$ smooth muscle, ${ }^{2)}$ connective tissue ${ }^{31}$ and endothelial cells. ${ }^{4}$ Lymphatics, ${ }^{5 /}$ nerves ${ }^{61}$ (1973) and fibroblasts? have also been implicated.

This study uses light and electron microscopy and histochemistry to describe features of Aschoff cells that may clarify their origin.
\end{abstract}

\section{Materials and Methods}

A total of 304 left atrial appendages, excised at the time of mitral val-

From the Department of Pathology, All India Institute of Medical Sciences, New Delhi, India. Address for reprint: P. Chopra, M.D., Department of Pathology, All India Institute of Medical Sciences, Ansari Nagar, New Delhi-1 10029, India.

Received for publication April 4, 1984. 
votomy, were analysed for the presence of AN. Out of the 304 samples, 102 were collected fresh. The specimen was divided into half with a sharp razor blade. One half was frozen, and $5 \mu$ thick sections were cut in the cryostat at $-20^{\circ} \mathrm{C}$. The section was then stained with toluidine blue and screened for the presence of AN. When present, the area of the section bearing them was carefully mapped. The corresponding region on the other half of the frozen, unfixed tissue was matched with the area on the frozen section having AN. This area was cut out with a sharp razor blade and processed for electron microscopy. Ten to 15 consecutive sections were cut and stored at $-20^{\circ} \mathrm{C}$ for purposes of histochemistry.

All samples were processed conventionally. After paraffin embedding, 4-5 $\mu$ thick consecutive sections were cut and stained with hematoxylin and eosin. AN were diagnosed using criteria applied by Saphir (1959). ${ }^{81}$ In 75 cases where appreciable numbers of AN were present, the sections were subjected to Masson's trichrome, phosphatungstic acid hematoxylin (PTAH) and alcian blue periodic acid Schiff stains. Of the 102 samples that were subjected to cryostat sectioning, 75 cases were stained for acid phosphatase (AP) ${ }^{9}$ and nonspecific esterase (NSE). ${ }^{101}$

From the samples that were frozen immediately, 70 cases were processed for electron microscopy. Of these, 10 cases where numerous AN were identified within thick sections were studied in detail. The tissues were processed conventionally and $2 \mu$ thick section of the tissues embedded in epoxy resin were cut on an LKB ultramicrotome. These were then stained with toluidine blue and/or polychrome and examined to determine the area to be studied. The blocks were trimmed accordingly, and ultrathin sections cut and examined under a Philips 300 electron microscope operated at 60-80 KV.

\section{RESULTS}

The number of AN within a specimen were graded arbitrarily. No AN were detected in $47 \%$ of the 304 cases analysed. In 50 cases $(16.4 \%)$ only stray mesenchymal cell collections bearing no distinct characteristics of Aschoff cells were noted in the subendocardium. Thus, in nearly $2 / 3$ of the total number of cases examined, no AN or only occasional ill-formed ones were present. In only $2 \%$ of the cases (6) were numerous AN encountered in the atrial tissue (Table I).

In all the cases, AN were located in the subendocardial tissue closely apposed to the myocardium and sometimes to the subendocardial smooth muscle. Only in 1 case were they encountered in the perivascular connective tissue within the myocardium. Most of the AN were well-formed, con- 
Table I. Distribution of Aschoff Nodules (AN) in Excised Left Atrial Appendage (LAA)

\begin{tabular}{|c|c|c|c|c|c|c|}
\hline \multirow{2}{*}{$\begin{array}{l}\text { No. of } \\
\text { AN in } \\
\text { LAA }\end{array}$} & \multicolumn{2}{|c|}{ Fresh Tissue } & \multicolumn{2}{|c|}{ Formalin Fixed Tissue } & \multicolumn{2}{|c|}{ Grand Total } \\
\hline & $\begin{array}{c}\text { Total No. } \\
102\end{array}$ & $\%$ & $\begin{array}{c}\text { Total No. } \\
202\end{array}$ & $\%$ & $\begin{array}{c}\text { Total No. } \\
304\end{array}$ & $\%$ \\
\hline Nil & 60 & 58.8 & 84 & 41.6 & 144 & 47.3 \\
\hline \pm & 10 & 9.8 & 40 & 19.8 & 50 & 16.4 \\
\hline+ & 10 & 9.8 & 30 & 14.8 & 40 & 13.1 \\
\hline$H$ & 7 & 6.8 & 25 & 12.3 & 32 & 10.5 \\
\hline $\mathrm{H}$ & 11 & 10.8 & 21 & 10.3 & 32 & 10.5 \\
\hline 世1 & 4 & 3.9 & 2 & 0.9 & 6 & 2.0 \\
\hline
\end{tabular}

taining Aschoff cells and very few lymphocytes and plasma cells in their periphery. Although the subendocardial tissue was loose, edematous and exhibited appreciable amounts of acid mucopolysaccharides, no fibrinoid necrosis was evident in any of the cases. Aschoff cells displayed red and violet blue cytoplasmic staining with Masson's and PTAH stains, respectively. They also exhibited strong positivity for AP and NSE.

In a large number of cases, the left atrial endocardium showed varying degrees of endocardial thickening, possibly as a result of organised thrombi. Fresh thrombi were encountered only in an occasional case. Moderate to severe myocardial hypertrophy was present in all cases. Varying grades of myocarditis showing infiltration by lymphocytes and histiocytes was invariably present. In a few cases, a few epithelioid cells including giant cells were also identified within these foci.

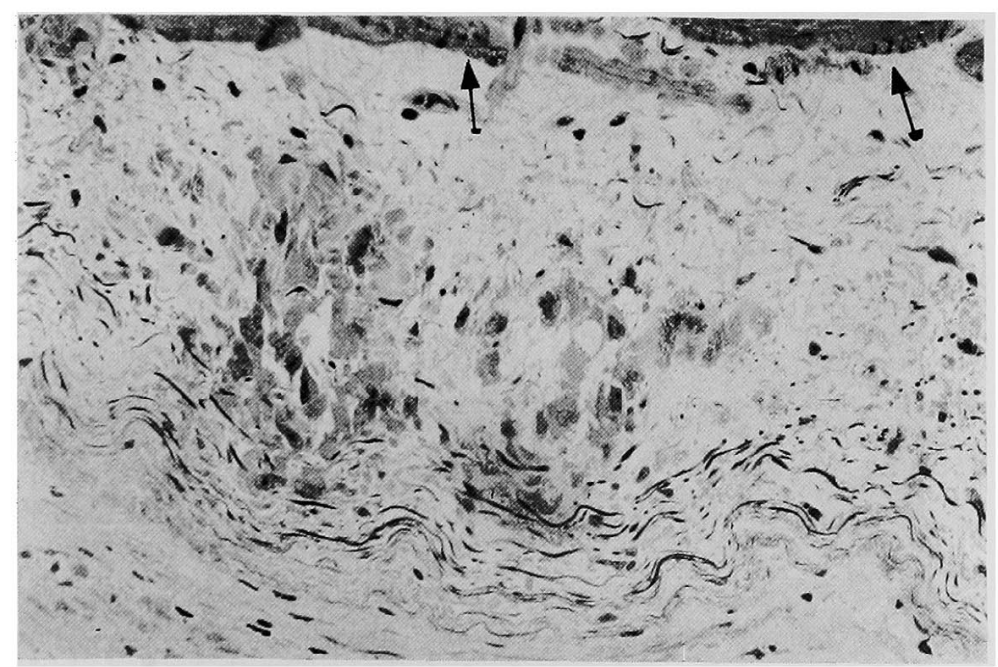

Fig. 1. Thick section $(2 \mu)$ of left atrial appendage showing Aschoff nodules (AN) in the subendocardium. Cardiac muscle is seen in upper part of the microphotograph (arrows). (toluidine blue $\times 90$ ) 


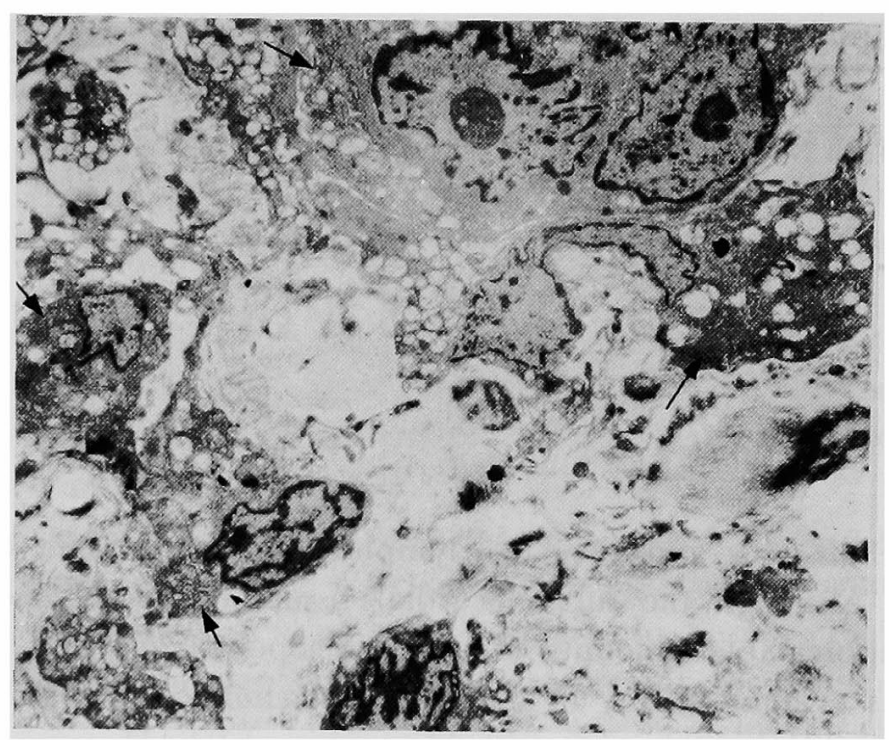

Fig. 2. Electron micrograph of AN showing uni- and binucleate Aschoff cells. Note prominent rough endoplasmic reticulum (RER) in most cells (arrows) and mitochondria situated mostly near the cell margins. Cell membrane shows some folds. Nuclear membrane identations and nucleoli are striking. $(\times 5,610)$

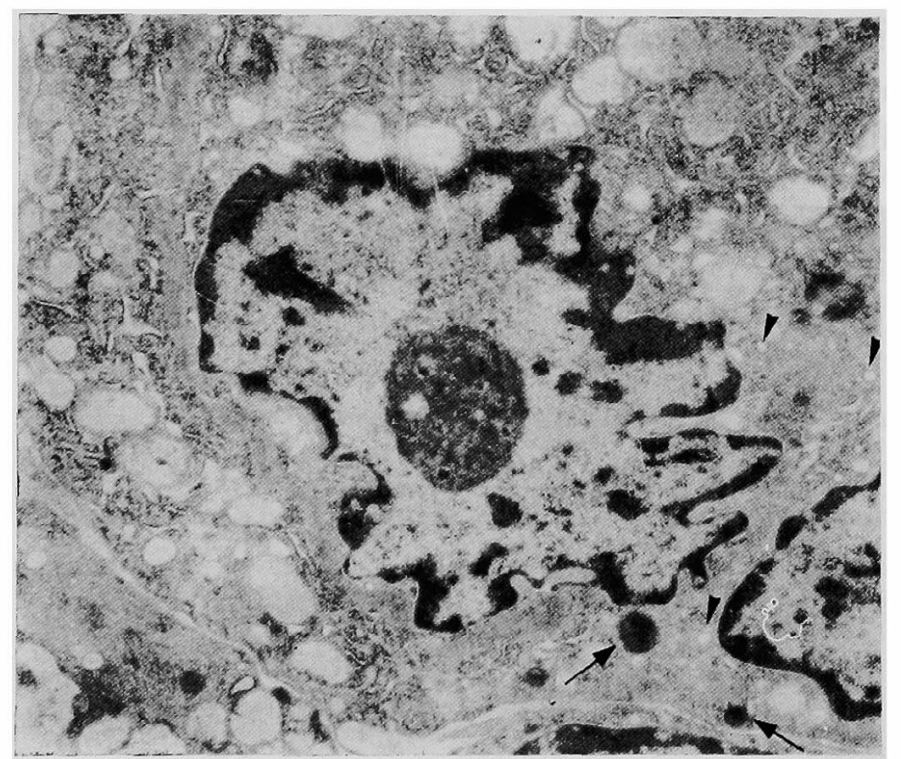

Fig. 3. Higher magnification of Fig. 2. Prominent RER having dilated cisterns admixed with mitochondria are frequent. Nuclear membrane shows deep invaginations and nucleoli are striking. Smooth surfaced vesicles (arrow heads) and occasional dense bodies are present (arrow). $(\times 9,900)$ 
Ultrastructurally, AN could be identified and were present in aggregates in the subendocardium (Fig. 1). The cells were mostly uninucleate, but multinucleate cells were not infrequent (Figs. 2-5). Aschoff cells have large ovoid nuclei with irregular nuclear membranes showing identations. Nu-

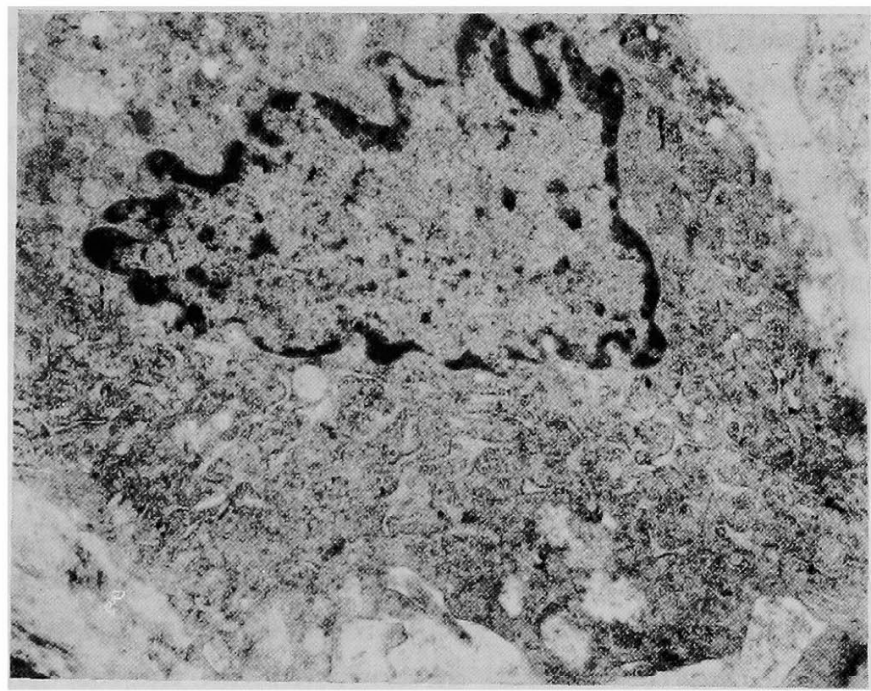

Fig. 4. Another Aschoff cell showing prominent RER some of which are distended with a light grey material. Ribosomes are increased while mitochondria are infrequent. Cell membrane is thrown into shallow folds. $(\times 11,700)$

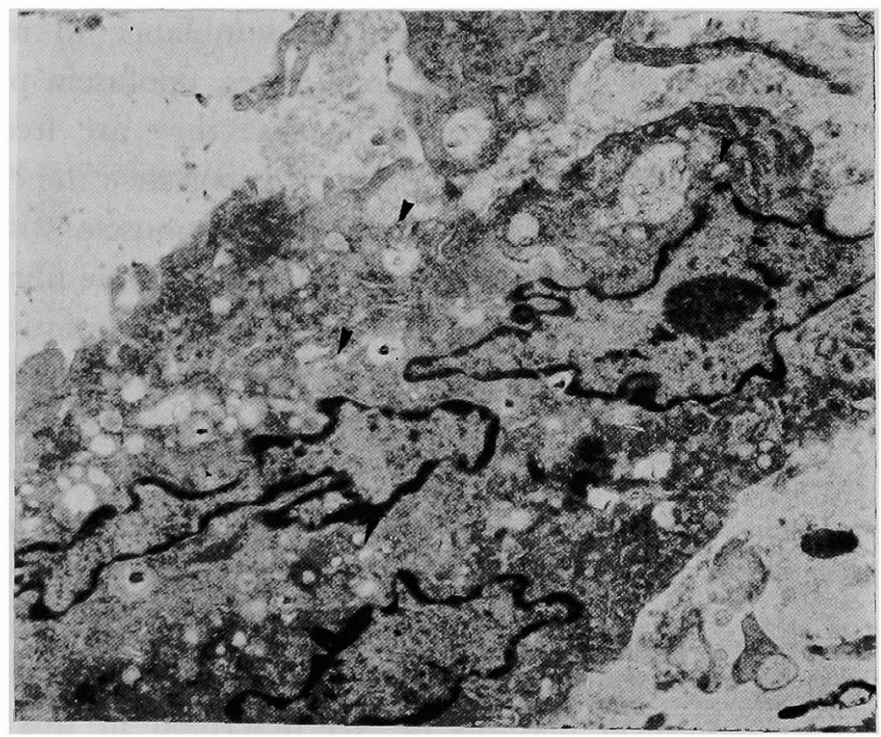

Fig. 5. Multinucleated Aschoff cell in an AN. Cell membrane is thrown into projections. Mitochondria ribosomes and RER are prominent. Smooth surfaced vesicles are present (arrow heads). $(\times 8,400)$ 
clear chromatin is irregularly dispersed with prominent nucleoli (Figs. 2-5). The cell membrane is thrown into slight projections (Figs. 4, 5). The cytoplasm contains a variable number of mitochondria of different sizes, predominantly towards the periphery of the cells (Figs. 2, 3, 5). Rough endoplasmic reticulum (RER) is striking in most cells (Figs. 3-5). Many of the RER profiles are distended with a light electron dense material within them (Figs. 3, 4). Occasional cells with abundant RER having plasmacytoid features were also seen. Smooth surfaced vesicles are present in some cells dispersed in the cytoplasm as well as beneath the cell surface (Figs. 3, 5). Ribosomes are increased (Figs. 3-5). In some cells, only occasional lipid droplets, dense bodies (Figs. 3, 5) and Golgi apparatus are also seen. A number of cells have varying amounts of collagen in their vicinity in which they seem to be embedded.

\section{Discussion}

The major controversy regarding the nature of Aschoff cells is between a myogenic ${ }^{1)}$ and a connective tissue origin. ${ }^{2)-7)}$ Proponents of the myogenic theory have based their conclusion on conventional microscopy where AN appear to bear a resemblance and/or a close relationship to myocardium and smooth muscle cells of the endocardium. Murphy ${ }^{11}$ has further strengthened this view by reporting that Aschoff cells resemble muscle cells with Masson's trichrome and PTAH stains. There are several objections to these observations. Ultrastructurally, these cells bear no resemblance to muscle cells. Also, if these indeed were degenerated muscle fibres, lipofuscin pigment and lipid droplets should have been detected because they are frequently encountered in damaged cardiac muscle. ${ }^{3)}$ In our experience the cytoplasm of several types of cells may acquire characteristics of muscle with Masson's trichrome and PTAH stains, which are not specific for muscle fibres.

On the other hand $\mathrm{AN}$ morphologically resemble an unique granuloma within the endocardium. ${ }^{3}$ ' Epithelioid cells compose a conventional, traditional granuloma. Epithelioid cells represent altered macrophages. Ultrastructurally, these cells have large amounts of RER, and well developed and swollen mitochondria. Phagocytosis and dense lysosome bodies are not typical or frequent. ${ }^{11)-13 !}$ These features are quite like those of fibroblasts except that latter have dilated cisterns of RER containing electron dense material and are frequently spindle shaped, lying in close proximity to and surrounded by collagen. Ultrastructural features of AN described in this study have several features that simulate both macrophages and fibroblasts. Some of these findings have been reported earlier. ${ }^{3), 14)}$ The resemblance to fibroblasts 
is evidenced by the facts that a) RER is prominent, b) dilated cisterns of RER containing a homogeneous electron dense material are frequent, c) mitochondria are prominent and d) collagen is present in close proximity to the Aschoff cells. The major feature that is dissimilar to fibroblasts is that the well formed Aschoff cells are polyhedral, round or polygonal. Typical spindle shape is lacking. In fact, Aschoff cells have a number of features of epithelioid cells. ${ }^{11-13)}$ It has been suggested that Anitschkow cells may represent an intermediate phase in the development of a macrophage or fibroblast from an undifferentiated mesenchymal cell.3),7),15) A number of experimental observations also have been made on the differentiation of human leukocytes, mononuclear leukocytes to fibroblasts, ${ }^{16)-18)}$

Histochemically, AN showed a strong reaction for both nonspecific esterase and acid phosphatase. Although no specific enzyme patterns are known for histiocytes, fibroblasts and myofibres, ${ }^{19)}$ dense bodies that represent lysosomes were not prominent or totally lacking.

Thus, it is likely that the AN arises from the mesenchymal tissues of the heart. These tissues in the post-streptococcal state undergo a transformation to cells that have resemblance to fibroblasts and histiocytes. A spccial predilection of the streptococcal antigens to valvular fibroconnective tissue is well documented. ${ }^{20}$ It is likely therefore, that the cross reactivity between streptococcal antigens and myocardial connective tissue causes alterations such that it is transformed to cells that have features of epithelioid cells and/or fibroblasts.

\section{Acknowledgment}

The author is grateful to Departments of Biophysics and Anatomy and Mr. Achhar Singh for electron microscopy.

\section{ReFERENCES}

1. Murphy GE: The characteristic rheumatic lesions of striated and of nonstriated or smooth muscle cells of the heart. Genesis of the lesions known as Aschoff bodies and those myogenic components known as Aschoff cells or as Anitschkow cells or myocytes. Medicine 42: 73, 1963

2. Becker CG, Murphy GE: Demonstration of contractile protein in endothelium and cells of the heart valves endocardium, intima, arteriosclerotic plaques and Aschoff bodies of rheumatic heart disease. Am J Pathol 55: 1, 1969

3. Wagner BM, Siew S: Studies in rheumatic fever. V. Significance of the human Anitschkow cell. Human Pathol 1 : 45, 1970

4. Pienaar JG, Price HM: Ultrastructure and origin of Anitschkow cell. Am J Pathol 51: 1063,1967

5. Wedum BG, McGuire JW: Origin of Aschoff body. Ann Rheum Dis 22: 127, 1963

6. Hutchins GM, Payne KT: Possible origin of myocardial Aschoff bodies of rheumatic fever 
from nerves. J Hopkins Med J 132: 315, 1973

7. Costero I, Barrose Mognel R, Chevez A, Monrey G, Contreras R: Rheumatic lesions in patients treated with cortisone. I. With special reference to endomyocarditis. Arch Inst Cardiol Mex 28: 155, 1958

8. Saphir O: The Aschoff nodule. Am J Clin Pathol 31: 534, 1959

9. Wachstein $\mathrm{M}$, Meisel $\mathrm{H}$ : Histochemistry of hepatic phosphatases at physiological $\mathrm{pH}$. Am J Clin Pathol 27: 13, 1957

10. Yam LT, Li CY, Crosby WH: Cytochemical methods for nonspecific esterase and peroxidase for identification of monocytes and granulocytes. Am J Clin Pathol 55: 283, 1971

11. Elias PM, Epsteir WL: Ultrastructural observations on experimentally induced foreign body and organized epithelioid cell granulomas in man. Am J Pathol 52: 2107, 1968

12. Turk TL, Badenoch Jones P, Parker D: Ultrastructural observation on epithelioid cells of granulomas induced by Zirconium in the guinea pig. J Pathol 124: 45, 1978

13. Williams GT: Isolated epithelioid cells from disaggregated BCG granulomas. An ultrastructural study. J Pathol 136: 1, 1982

14. Lannigan R, Zaki SA: Ultrastructure of lesions of rheumatic carditis. J Pathol \& Bacteriol 97: 449, 1967

15. Nelson DS: Anatomical distribution and life history of macrophages. in Macrophages and Immunity, ed by Neuberger A, Tatum EL, Noth Holland Publishing Co, Amsterdam, London, p 36, 1969

16. Petrakis NL, Davis M, Lucia SP: The in vivo differentiation of human leucocytes into histiocytes, fibroblast fat cells in subcutaneous diffusion chamber. Blood 17:109, 1961

17. Ross R, Lillywhite JW: Fate of buffy coat cells grown in subcutaneously implanted diffusion chambers. Lab Invest 14: 1568, 1965

18. Gillman $\mathrm{T}$, Wright $\mathrm{LJ}$ : Autoradiographic evidence suggesting in vivo transformation of some blood mononuclears in repair and fibrosis. Nature 209: 1086, 1966

19. Wagner BM: Studies in rheumatic fever. III. Histochemical reactivity of the Aschoff body. Ann NY Acad Sci 86: 992, 1960

20. Dudding BA, Ayoub EM: Persistence of group A antibody in patients with rheumatic valvular disease. J Exp Med 128: 1081, 1968 